Florida International University FIU Digital Commons

$8-2-2008$

\title{
Incomplete Information In a Long Run Risks Model of Asset Pricing
}

Prasad V. Bidarkota

Department of Economics, Florida International University, bidarkot@fiu.edu

Follow this and additional works at: https://digitalcommons.fiu.edu/economics_wps

\section{Recommended Citation}

Bidarkota, Prasad V., "Incomplete Information In a Long Run Risks Model of Asset Pricing" (2008). Economics Research Working Paper Series. 45 .

https://digitalcommons.fiu.edu/economics_wps/45 


\title{
Incomplete Information In a Long Run Risks Model of Asset Pricing
}

\author{
Prasad V. Bidarkota* \\ Department of Economics, Florida International University
}

\begin{abstract}
We study the effects of incorporating incomplete information in the recently developed long run risks model of asset pricing. Studying the effects of incomplete information in such a setting is tractable, especially in the homoskedastic case with no fluctuating economic uncertainty. The incomplete information model is solved using approximate analytical methods as in the complete information framework analyzed in the literature. Model implications on moments of endogenous variables of interest including rates of return are compared in the long run risks model with and without incomplete information.
\end{abstract}

Key phrases: asset pricing; long run risks; incomplete information; Kalman filter; equity returns; riskfree returns

JEL classification: G12, G13, E43

February 7, 2008

\footnotetext{
* Department of Economics, University Park DM 320A, Florida International University, Miami, FL 33199, USA; Tel: +1-305-348-6362; Fax: +1-305-348-1524;

E-mail address: bidarkot@fiu.edu
} 


\section{INTRODUCTION}

Recent work on long run risks and their implications for asset pricing pioneered by Bansal and Yaron (2004) shows a great deal of promise in resolving several empirical puzzles in asset pricing. An abundance of research attention is currently focused on exploring implications of long run risks in a variety of contexts. Bansal (2007) provides a brief review of this literature. See also Hansen, Heaton and Li (2005).

The structure of the long run risks model in Bansal and Yaron (2004) is well suited for an exploration of the effects of incomplete information in asset pricing context. The potential importance of the effects of incomplete information in asset pricing has been recognized in early work by Dothan and Feldman (1986), Detemple $(1986,1989)$, Gennotte (1986), and more recently, by Brennan and Xia (2001). This literature studies incomplete information in a linear Gaussian setting wherein the classic Kalman filter provides an optimal Bayesian updating rule for learning about the unobservable dividend drift rate with the arrival of new information on dividends each period. More recently, David (1997) and Veronesi (2004) study asset pricing with incomplete information in a non-Gaussian setting where the unobservable dividend growth rate undergoes jumps, driven either by a Markov switching or Poisson arrival process.

A linear Gaussian conditionally homoskedastic model (the no fluctuating economic uncertainty case in Bansal and Yaron 2004) with incomplete information is particularly amenable to analysis. This is because, with conditional homoskedasticity, the variance of the filter density of the state vector becomes time invariant once the Kalman

filter has reached steady state. The approximate analytical solution method in Bansal and Yaron (2004) can then be used to solve the model. 
In this paper we explore the implications of incorporating incomplete information in the long run risks model in a linear Gaussian homoskedastic framework. We derive approximate analytical solution to the model in this setting using the methods in Bansal and Yaron (2004). We quantify the implications of incomplete information on the moments of risk premium and risk free rate by making a detailed comparison with the complete information case.

The paper is organized as follows. We describe the economic environment, the specification of the exogenous stochastic process for consumption and dividend growth rates, as well as solution to the asset pricing model in section 2 . We parameterize the model and analyze its empirical implications in section 3 . We conclude in section 4 with some key observations derived from the study.

\section{THE MODEL}

Is this section we lay out the economic environment, including specification of exogenous stochastic processes and information structure, and present solution to the asset pricing model.

\subsection{Model Economy}

Our model economy is very similar to the one studied in Bansal and Yaron (2004). The first order condition for a representative agent with Epstein and Zin (1989) and Weil (1989) recursive preferences satisfies:

$$
\mathrm{E}_{\mathrm{t}}\left[\delta^{\theta} \mathrm{G}_{\mathrm{t}+1}^{-\frac{\theta}{\psi}} \mathrm{R}_{\mathrm{a}, \mathrm{t}+1}^{-(1-\theta)} \mathrm{R}_{\mathrm{i}, \mathrm{t}+1}\right]=1
$$


for any asset with gross returns $R_{i, t+1}$. Here in this equation, $G_{t+1}$ is the aggregate gross growth rate of consumption, $0<\delta<1$ is the time discount factor, $\psi \geq 0$ is the elasticity of intertemporal substitution (IES), and $\theta \equiv \frac{1-\gamma}{1-\frac{1}{\psi}}$ with $\gamma \geq 0$ being the risk aversion parameter. The intertemporal marginal rate of substitution (IMRS) $\delta^{\theta} \mathrm{G}_{\mathrm{t}+1}^{-\frac{\theta}{\psi}} \mathrm{R}_{\mathrm{a}, \mathrm{t}+1}^{-(1-\theta)}$ is alternatively referred to in the literature as the pricing kernel or the stochastic discount factor.

The above first-order condition applies in turn to an asset with unobservable gross returns $R_{a, t+1}$ that pays aggregate consumption as dividends each period, to an asset with observable gross returns $R_{m, t+1}$ that pays aggregate dividends on the market portfolio, as well as an asset with observable risk free returns $R_{f, t}$ that pays one unit of aggregate consumption.

Let $\mathrm{z}_{\mathrm{t}} \equiv \ln \left(\mathrm{P}_{\mathrm{a}, \mathrm{t}} / \mathrm{C}_{\mathrm{t}}\right)$ be the $\log$ price-consumption ratio and $\mathrm{r}_{\mathrm{a}, \mathrm{t}+1} \equiv \ln \left(\mathrm{R}_{\mathrm{a}, \mathrm{t}+1}\right)$ be the continuous return. From the definition of gross returns, one can utilize first-order Taylor's series approximation to write:

$$
\mathrm{r}_{\mathrm{a}, \mathrm{t}+1} \cong \mathrm{k}_{0}+\mathrm{k}_{1} \mathrm{z}_{\mathrm{t}+1}-\mathrm{z}_{\mathrm{t}}+\mathrm{g}_{\mathrm{t}+1}
$$

where $\mathrm{k}_{0}$ and $\mathrm{k}_{1}$ are approximating constants that depend only on the average level of z. Similarly, we define analogous quantities, namely $z_{m, t} \equiv \ln \left(P_{m, t} / D_{t}\right)$ and 
$r_{m, t+1} \equiv \ln \left(R_{m, t+1}\right)$ on the market portfolio. The following equation then holds approximately for the continuous returns on the market portfolio:

$$
\mathrm{r}_{\mathrm{m}, \mathrm{t}+1} \cong \mathrm{k}_{0, \mathrm{~m}}+\mathrm{k}_{1, \mathrm{~m}} \mathrm{z}_{\mathrm{m}, \mathrm{t}+1}-\mathrm{z}_{\mathrm{m}, \mathrm{t}}+\mathrm{g}_{\mathrm{d}, \mathrm{t}+1}
$$

where the approximating constants $\mathrm{k}_{0, \mathrm{~m}}$ and $\mathrm{k}_{1, \mathrm{~m}}$ now depend only on the average level of the $\log$ price-dividend ratio $\mathrm{z}_{\mathrm{m}}$.

The logarithm of the IMRS is easily seen to be:

$$
\mathrm{m}_{\mathrm{t}+1}=\theta \ln (\delta)-\frac{\theta}{\psi} \mathrm{g}_{\mathrm{t}+1}+(\theta-1) \mathrm{r}_{\mathrm{a}, \mathrm{t}+1}
$$

where $g_{t+1} \equiv \ln \left(G_{t+1}\right)$ is the log of gross consumption growth rate.

\subsection{Consumption and Dividends Growth Rate Processes under Complete}

\section{Information}

We assume that consumption and dividend growth rates stochastically evolve according to the following process:

$$
\begin{aligned}
& \mathrm{g}_{\mathrm{t}+1}=\mathrm{x}_{\mathrm{t}}+\sigma \eta_{\mathrm{t}+1} \\
& \mathrm{x}_{\mathrm{t}+1}-\mu=\rho\left(\mathrm{x}_{\mathrm{t}}-\mu\right)+\varphi_{\mathrm{e}} \sigma \mathrm{e}_{\mathrm{t}+1} \\
& \mathrm{~g}_{\mathrm{d}, \mathrm{t}+1}=\phi \mathrm{x}_{\mathrm{t}}+\varphi_{\mathrm{d}} \sigma \mathrm{u}_{\mathrm{t}+1} \\
& \eta_{\mathrm{t}+1}, \mathrm{e}_{\mathrm{t}+1}, \mathrm{u}_{\mathrm{t}+1} \sim \operatorname{iid} \mathrm{N}(0,1)
\end{aligned}
$$

with the three shocks $\eta_{t+1}, e_{t+1}$, and $u_{t+1}$ being mutually independent. This is very similar to the homoskedastic process used in Bansal and Yaron (2004). The only difference is in the treatment of the non-zero mean term. Unlike above, in Bansal and Yaron (2004), $x_{t}$ is a zero mean process while the equations for $g_{t+1}$ and $g_{d, t+1}$ have 
non-zero $\mu$ and $\mu_{\mathrm{d}}$ respectively appearing as additive terms on the r.h.s. Our process above is a constrained version of this case, where we restrict $\mu_{d}=\phi \mu$.

Here, $x_{t}$ is interpreted as the conditional growth rate of consumption assumed known at time $\mathrm{t}$ and $\sigma^{2}$ is its conditional variance. We refer to this as the complete information case.

Under complete information the expected growth rate of consumption $\mathrm{x}_{\mathrm{t}}$ is the state variable. The endogenous solution to the price dividend ratios on claims to aggregate consumption and the market returns can be fully characterized in terms of this single state variable.

Following the solution method in Bansal and Yaron (2004) closely, we conjecture the following linear solution forms for $\mathrm{z}_{\mathrm{t}}$, the $\log$ price-dividend ratio on a claim to aggregate consumption and for $\mathrm{z}_{\mathrm{t}, \mathrm{m}}$, the $\log$ price-dividend ratio on a claim to market returns:

$$
\begin{aligned}
& \mathrm{z}_{\mathrm{t}}=\mathrm{A}_{0}+\mathrm{A}_{1} \mathrm{x}_{\mathrm{t}} \\
& \mathrm{z}_{\mathrm{t}, \mathrm{m}}=\mathrm{A}_{0, \mathrm{~m}}+\mathrm{A}_{1, \mathrm{~m}} \mathrm{x}_{\mathrm{t}} .
\end{aligned}
$$

One can now easily derive the solution coefficients for the price-dividend ratios. These are given by:

$$
\mathrm{A}_{1}=\frac{1-1 / \psi}{1-\mathrm{k}_{1} \rho}, \quad \mathrm{A}_{1, \mathrm{~m}}=\frac{\phi-1 / \psi}{1-\mathrm{k}_{1, \mathrm{~m}} \rho}
$$

In the complete information case the formulae for the unconditional mean and variance of the risk premium on the market portfolio and of the risk free rate, as well as the unconditional variance of the log price-dividend ratio on the market portfolio can be 
worked out as special (homoskedastic) cases of the more general formulae derived in the time-varying uncertainty case in the appendix to Bansal and Yaron (2004).

\subsection{Consumption and Dividends Growth Rate Processes under Incomplete Information}

We assume that consumption and dividend growth rates stochastically evolve according to the following process:

$$
\begin{aligned}
& g_{t}=x_{t}+\sigma \eta_{t} \\
& x_{t}-\mu=\rho\left(x_{t-1}-\mu\right)+\varphi_{e} \sigma e_{t} \\
& g_{d, t}=\phi x_{t}+\varphi_{d} \sigma u_{t} \\
& \eta_{t}, e_{t}, u_{t} \sim \operatorname{iidN}(0,1)
\end{aligned}
$$

with the three shocks $\eta_{t}, e_{t}$, and $u_{t}$ being mutually independent.

We interpret the model above as a state space model, with $x_{t}$ being the unobservable state variable driven by the dynamics in Equation (8b) with the signal shock $e_{t}$. Equations (8a) and (8c) are the measurement equations, with consumption and dividend growth rates $g_{t}$ and $g_{d, t}$ being observable. Here, $x_{t}$ can only be inferred probabilistically through a Bayesian filtering process. Since the model is linear Gaussian, the conditional filter density of $\mathrm{x}_{\mathrm{t}}$ is itself Gaussian and hence is completely characterized by its mean and variance. These are recursively given by the classical Kalman filter recursions. We refer to this as the incomplete information case.

In the rest of the paper, for the sake of analytical simplicity, we assume that investors ignore the measurement Equation (8c) while trying to learn about the unobservable $\mathrm{x}_{\mathrm{t}}$. Therefore, Bayesian filtering on the investors' part is done treating 
Equation (8a) as the measurement equation and Equation (8b) as the state transition equation. For all other purposes, namely in trying to derives rates of return and risk premia on the market portfolio, investors are assumed to fully take the process for the dividend growth rates specified in Equation (8c) into account.

Let $Y_{t} \equiv\left\{g_{1}, g_{2}, \ldots, g_{t}\right\}$ denote the history of consumption growth rates up to and including the value at time $t$. Then the filter density of $x_{t}, p\left(x_{t} \mid Y_{t}\right) \sim N\left(a_{t}, P_{t}\right)$ can be characterized by the filter mean $a_{t}$ and the filter variance $P_{t}$. In this homosekdastic model, once the filter reaches steady state, the filter variance stabilizes to a constant value $\overline{\mathrm{P}}$. The Kalman filter updating formula for the filter mean can then easily be shown to be (see, for instance, Harvey 1992, Ch.3):

$$
a_{t}=(1-\rho) \mu+\rho a_{t-1}+\left(\frac{\rho^{2} \overline{\mathrm{P}}+\varphi_{\mathrm{e}}^{2} \sigma^{2}}{\rho^{2} \overline{\mathrm{P}}+\varphi_{\mathrm{e}}^{2} \sigma^{2}+\sigma^{2}}\right)\left\{\rho\left(\mathrm{x}_{\mathrm{t}-1}-\mathrm{a}_{\mathrm{t}-1}\right)+\varphi_{\mathrm{e}} \sigma \mathrm{e}_{\mathrm{t}}+\sigma \eta_{\mathrm{t}}\right\} .
$$

The steady state filter variance can be obtained by solving the following Riccati equation for $\mathrm{P}_{\mathrm{t}}=\mathrm{P}_{\mathrm{t}-1}=\overline{\mathrm{P}}$ :

$$
P_{t}=\frac{\left(\rho^{2} P_{t-1}+\varphi_{e}^{2} \sigma^{2}\right) \sigma^{2}}{\rho^{2} P_{t-1}+\varphi_{e}^{2} \sigma^{2}+\sigma^{2}}
$$

The resulting quadratic equation for $\overline{\mathrm{P}}$ has only one positive root which we take to be the steady state filter variance.

Under incomplete information the filter mean of $x_{t}$ is the relevant state variable. The endogenous solution to the price dividend ratios on claims to aggregate consumption and the market returns can be fully characterized in terms of the filter mean. 
We conjecture the following linear solution forms for $z_{t}$, the log price-dividend ratio on a claim to aggregate consumption and for $\mathrm{z}_{\mathrm{t}, \mathrm{m}}$, the $\log$ price-dividend ratio on a claim to market returns:

$$
\begin{aligned}
& z_{t}=A_{0}+A_{1} a_{t} \\
& z_{t, m}=A_{0, m}+A_{1, m} a_{t} .
\end{aligned}
$$

Following the methods in Bansal and Yaron (2004), one can easily derive the solution coefficients for the price-dividend ratios. These are given by:

$$
A_{1}=\frac{\rho(1-1 / \psi)}{1-\mathrm{k}_{1} \rho}, \quad \mathrm{A}_{1, \mathrm{~m}}=\frac{\rho(1-1 / \psi)}{1-\mathrm{k}_{1, \mathrm{~m}} \rho} .
$$

In the incomplete information case, using methods identical to those in Bansal and Yaron (2004) but recognizing that the relevant state variable is now, instead of the unobservable $x_{t}$, its filter mean $a_{t}$, one can derive expressions for the relevant moments of endogenous variables of interest. These are given in Appendix B.

\section{ANALYSIS OF MODEL IMPLICATIONS}

In this section we report parameter values used to specify preferences and exogenous stochastic process for consumption and dividend growth rates. We then present model implications for various endogenous quantities of interest, including rates of return.

\subsection{Model Parameterization}

The asset pricing model has three preference parameters $\delta, \gamma$ and $\psi$, with $\theta$ being determined by the latter two. It also has six parameters describing the joint stochastic processes for consumption and dividend growth rates. In what follows, we choose parameter values given in Bansal and Yaron (2004). These are presented in Table 
1. Subsequent empirical implications of the model will be explored for various alternative values of the risk aversion parameter $\gamma$ and the IES parameter $\psi$ in addition to those listed in Table 1.

The preference and stochastic process parameters are identical for the complete and incomplete information cases. In the latter case, the steady state filter variance obtained by solving the Riccati Equation (9b) works out to be $1.683 \mathrm{e}-6$.

The approximating constants $\mathrm{k}_{0}, \mathrm{k}_{1}, \mathrm{k}_{0, \mathrm{~m}}$, and $\mathrm{k}_{1, \mathrm{~m}}$ appearing in Equations (2)-(3) depend on the average levels of $z$ and $z_{m}$ which are themselves endogenous. Therefore, these constants can be solved for endogenously, by solving an equation such as Equation (10) in Bansal, Kiku and Yaron (2006). For our chosen parameter values, the approximating constants $\mathrm{k}_{1}$ and $\mathrm{k}_{1, \mathrm{~m}}$ work out to be 0.9990 and $0.9967 .{ }^{1}$ In the incomplete information case, these constants work out to be 0.9981 and 0.9997 respectively.

\subsection{Analysis of Unconditional Moments of Model-Implied Variables of Interest}

Table 2 reports the unconditional means and variances of the risk premium and the risk free rate, as well as the unconditional variance of the log price-dividend ratio on the market portfolio for various values of $\gamma$ and $\psi$ in both the complete and incomplete information cases. For ease of comparison we also reproduce these statistics estimated from data from Table IV in Bansal and Yaron (2004).

\footnotetext{
${ }^{1}$ I thank Ravi Bansal for bringing this point to my attention and Dana Kiku for providing implied values of the approximating constants for the model parameterization used in Bansal and Yaron (2004).
} 
Results reported in the complete information case are comparable to those in Table II of Bansal and Yaron (2004) with no fluctuating economic uncertainty. Differences between the results can be directly attributed to the slightly different specification of our stochastic process for consumption and dividend growth rates as noted in the paragraph immediately following Equations (5) above. The most significant difference between the results is that our complete information model ends up generating about 0.30 percent per annum higher risk premium on average across the various parameter specifications considered. This is because our stochastic process and our parameterization implies that the average dividend growth rate is $\phi \mu$ which from Table 1 works out to be 5.4 percent per annum rather than 1.8 percent per annum implied by the process in Bansal and Yaron (2004).

Adding incomplete information to the long risks model shows that all the statistics reported in Table 2 uniformly decline in magnitude. Specifically, the risk premium is either negative or very close to zero and the risk free rate declines by about 0.6 to as much as 1.4 percent per annum. The volatility of the risk premium declines to about 12.5 percent per annum for all values of $\gamma$ and $\psi$, while the volatility of the risk free rate reduces to about 0.24 or 0.73 percent per annum depending on the parameter values. Finally, the volatility of the log price dividend ratio reduces to 0.05 percent per annum or less.

The decline in volatility of the risk free rate and the log price dividend ratio is easily rationalized. Equations (B1) and (B2) provide formulae for these volatilities in the incomplete information case. In the complete information case, these formulae have $\sigma^{2}\left(x_{t}\right)$ rather than $\sigma^{2}\left(\mu_{t}\right)$ terms appear on the rhs, since $x_{t}$, not $\mu_{t}$, is the relevant 
state variable in this instance. ${ }^{2}$ For our model parameterization, $\sigma^{2}\left(\mathrm{x}_{\mathrm{t}}\right)$ is $2.834 \mathrm{e}-6$ while $\sigma^{2}\left(\mu_{t}\right)$ is only $1.152 \mathrm{e}-6$.

Overall, it appears that adding incomplete information to the long run risks model moves the mean risk free rate (and for some parameter values its volatility) in the right direction to match up with the corresponding statistic in the data. However, along all other dimensions (i.e. in terms of the mean and volatility of the risk premium and the volatility of the log price-dividend ratio), the model performance deteriorates.

\section{CONCLUSIONS}

We explored the effects of incomplete information in the benchmark long run risks model of asset pricing due to Bansal and Yaron (2004). We compared the homoskedastic (no fluctuating economic uncertainty) complete information model analyzed in the above study with an incomplete information version. We solved the asst pricing model in the incomplete information case using the approximate analytical methods exposited in the above study.

We analyzed the implications of incorporating incomplete information on the means and volatilities of model-implied rates of return on risk free asset and the market portfolio, as well as the volatility of the log price dividend ratio. Our results show that incomplete information helps to move the model implications on the risk free rate closer to the data (at least for some parameter values) but that the model performance deteriorates significantly in terms of all other moments.

${ }^{2}$ Also, for the volatility of the risk free rate in the complete information case, $\rho^{2}$ is replaced by 1 on the rhs but this has little impact since $\rho$ is calibrated to be 0.979 . 


\section{APPENDIX A}

In this appendix we provide expressions for some quantities of interest, namely the innovations to the return on the aggregate consumption claim and the IMRS, as well as the risk premium on the aggregate consumption claim in the incomplete information case. The derivations rely on methods identical to those in Bansal and Yaron (2004) but recognizing that the relevant state variable in the incomplete information case is now, instead of the unobservable $x_{t}$, its filter mean $a_{t}$. The steady state variance of the filter density is given by $\overline{\mathrm{P}}$. We use the notation $K \equiv \frac{\left(\rho^{2} \overline{\mathrm{P}}+\varphi_{\mathrm{e}}^{2} \sigma^{2}\right) \sigma^{2}}{\rho^{2} \overline{\mathrm{P}}+\varphi_{\mathrm{e}}^{2} \sigma^{2}+\sigma^{2}}$ in what follows.

The innovation to the return on the consumption claim can be shown to be:

$$
r_{a, t+1}-E_{t}\left(r_{a, t+1}\right)=\left[1+k_{1} A_{1} K \rrbracket \rho\left(x_{t}-a_{t}\right)+\varphi_{e} \sigma e_{t+1}+\sigma \eta_{t+1}\right] .
$$

It then easily follows that $\operatorname{var}_{t}\left(r_{a, t+1}\right)=\left[1+k_{1} A_{1} K\right]^{2}\left[\rho^{2} \bar{P}+\varphi_{e}^{2} \sigma^{2}+\sigma^{2}\right]$.

The innovation to the IMRS can be shown to be:

$$
\mathrm{m}_{\mathrm{t}+1}-\mathrm{E}_{\mathrm{t}}\left(\mathrm{m}_{\mathrm{t}+1}\right)=\left[\frac{-\theta}{\psi}+(\theta-1)\left\{1+\mathrm{k}_{1} \mathrm{~A}_{1} \mathrm{~K}\right\}\right]\left[\rho\left(\mathrm{x}_{\mathrm{t}}-\mathrm{a}_{\mathrm{t}}\right)+\varphi_{\mathrm{e}} \sigma \mathrm{e}_{\mathrm{t}+1}+\sigma \eta_{\mathrm{t}+1}\right] .
$$

The risk premium for holding the aggregate consumption claim is determined by the conditional covariance of its return with the IMRS. Thus, $E_{t}\left(r_{a, t+1}-r_{f, t}\right)=-\operatorname{cov}_{t}\left\lfloor m_{t+1}-E_{t}\left(m_{t+1}\right), r_{a, t+1}-E_{t}\left(r_{a, t+1}\right)\right\rfloor-0.5 \operatorname{var}_{t}\left(r_{a, t+1}\right)$. This can be shown to be:

$\mathrm{E}_{\mathrm{t}}\left(\mathrm{r}_{\mathrm{a}, \mathrm{t}+1}-\mathrm{r}_{\mathrm{f}, \mathrm{t}}\right)=-\left[1+\mathrm{k}_{1} \mathrm{~A}_{1} \mathrm{~K}\right]\left[\frac{-\theta}{\psi}+(\theta-0.5)\left\{1+\mathrm{k}_{1} \mathrm{~A}_{1} \mathrm{~K}\right\}\right]\left[\rho^{2} \overline{\mathrm{P}}+\varphi_{\mathrm{e}}^{2} \sigma^{2}+\sigma^{2}\right]$. 


\section{APPENDIX B}

In this appendix we provide expressions for the unconditional mean and variance of the risk premium on the market portfolio and of the risk free rate, as well as the unconditional variance of the log price-dividend ratio on the market portfolio in the incomplete information case. The derivations rely on methods identical to those in Bansal and Yaron (2004) but recognizing that the relevant state variable in the incomplete information case is now, instead of the unobservable $x_{t}$, its filter mean $a_{t}$. The steady state variance of the filter density is given by $\overline{\mathrm{P}}$. We use the following notation in what follows. Let $\mathrm{F} \equiv \rho^{2} \overline{\mathrm{P}}+\varphi_{\mathrm{e}}^{2} \sigma^{2}+\sigma^{2}$ and $\mathrm{K} \equiv \frac{\left(\rho^{2} \overline{\mathrm{P}}+\varphi_{\mathrm{e}}^{2} \sigma^{2}\right) \sigma^{2}}{\rho^{2} \overline{\mathrm{P}}+\varphi_{\mathrm{e}}^{2} \sigma^{2}+\sigma^{2}}$.

Then one can show that $\sigma^{2}\left(x_{t}\right)=\frac{\varphi_{\mathrm{e}}^{2} \sigma^{2}}{1-\rho^{2}}, \quad \sigma^{2}\left(a_{t}\right)=\frac{K^{2} F}{1-\rho^{2}}, \quad$ and $\operatorname{cov} \operatorname{ar}\left(x_{t}, a_{t}\right)=\frac{K \varphi_{e}^{2} \sigma^{2}}{1-\rho^{2}}$

The unconditional variance of the $\log$ of the price-dividend ratio on the market portfolio can be shown to be:

$$
\sigma^{2}\left(\mathrm{z}_{\mathrm{m}, \mathrm{t}}\right)=\mathrm{A}_{1, \mathrm{~m}}^{2} \sigma^{2}\left(\mathrm{a}_{\mathrm{t}}\right)
$$

The unconditional variance of the risk free rate can be shown to be:

$$
\sigma^{2}\left(\mathrm{R}_{\mathrm{f}}\right)=\frac{\rho^{2}}{\psi^{2}} \sigma^{2}\left(\mathrm{a}_{\mathrm{t}}\right)
$$

Let $\mathrm{A}=1+\mathrm{k}_{1} \mathrm{~A}_{1} \mathrm{~K}$ and $\mathrm{B}=\left(\frac{-\theta}{\psi}+(\theta-1) \mathrm{A}\right)$. Then unconditional mean risk free rate can be shown to be: 


$$
\mathrm{E}\left(\mathrm{r}_{\mathrm{f}, \mathrm{t}}\right)=-\ln (\delta)+\frac{\mu}{\psi}-\frac{(1-\theta) \mathrm{AF}}{\theta}\left[\frac{-\theta}{\psi}+(\theta-0.5) \mathrm{A}\right]-\frac{0.5 \mathrm{FB}^{2}}{\theta} .
$$

Let $\mathrm{C}=\mathrm{k}_{1, \mathrm{~m}} \mathrm{~A}_{1, \mathrm{~m}} \mathrm{~K}+\phi$. Then unconditional mean risk premium on the market portfolio can be shown to be:

$$
\begin{gathered}
E\left(r_{m, t+1}-r_{f, t}\right)=-B C K F-k_{1, m} A_{1, m} K B \sigma^{2}-0.5 C^{2} \rho^{2} \bar{P}-0.5 C^{2} \varphi_{e}^{2} \sigma^{2} \\
-0.5\left(k_{1, m} A_{1, m} K\right)^{2} \sigma^{2}-0.5 \varphi_{d}^{2} \sigma^{2}
\end{gathered} .
$$

Let $\mathrm{D}_{0} \equiv-\left[\mathrm{A}_{1, \mathrm{~m}}\left(\mathrm{k}_{1, \mathrm{~m}} \rho-1\right)+\phi \rho\right] \mu, \quad \mathrm{D}_{1} \equiv \mathrm{C} \rho, \mathrm{D}_{2} \equiv-\left[\mathrm{k}_{1, \mathrm{~m}} \mathrm{~A}_{1, \mathrm{~m}} \mathrm{~K}\right] \rho, \mathrm{D}_{3} \equiv \mathrm{C}$, and $\mathrm{D}_{4} \equiv \mathrm{k}_{1, \mathrm{~m}} \mathrm{~A}_{1, \mathrm{~m}} \mathrm{~K}$. Then, unconditional variance of return on the market portfolio can be shown to be:

$\sigma^{2}\left(r_{m, t+1}\right)=D_{1}^{2} \sigma^{2}\left(x_{t}\right)+D_{2}^{2} \sigma^{2}\left(a_{t}\right)+2 D_{1} D_{2} \operatorname{cov} \operatorname{ar}\left(x_{t}, a_{t}\right)+D_{3}^{2} \varphi_{e}^{2} \sigma^{2}+D_{4}^{2} \sigma^{2}+\varphi_{d}^{2} \sigma^{2}$.

\section{REFERENCES}

Bansal, R., 2007. Long-run risks and financial markets, NBER Working Paper 13196.

Bansal, R. and A. Yaron, 2004. Risks for the long run: a potential resolution of asset pricing puzzles, Journal of Finance, Vol. LIX, No. 4, 1481-1509.

Bansal, R., D. Kiku and A. Yaron, 2006. Risks for the long run: estimation and inference, Unpublished Manuscript, Fuqua School, Duke University.

Brennan, M.J. and Y. Xia, 2001. Stock price volatility and equity premium, Journal of Monetary Economics 47, 249-283.

David, A., 1997. Fluctuating confidence in stock markets: Implications for returns and volatility, Journal of Financial and Quantitative Analysis, Vol.32, No.4, 427-462. 
Detemple, J.B., 1991. Further results on asset pricing with incomplete information, Journal of Economic Dynamics and Control 15, 425-453. , 1986. Asset pricing in a production economy with incomplete information, Journal of Finance, Vol.41, No.3, 383-391.

Dothan, M.U. and D. Feldman, 1986. Equilibrium interest rates and multiperiod bonds in a partially observable economy, Journal of Finance, Vol.41, No.2, 369-382.

Epstein, L.G. and S.E. Zin, 1989. Substitution, risk aversion, and the temporal behavior of consumption and asset returns: a theoretical framework, Econometrica, Vol.57, No.4, 937-969.

Gennotte, G., 1986. Optimal portfolio choice under incomplete information, Journal of Finance, Vol.41, No., 733-746.

Hansen, L.P., J.C. Heaton and N. Li, 2005. Consumption strikes back? Unpublished Manuscript, University of Chicago.

Harvey, A.C., 1992. Forecasting, Structural Time Series Models and the Kalman Filter, Cambridge University Press, Cambridge, UK.

Veronesi, P., 2004. Belief dependent utilities, aversion to state uncertainty, and asset prices, Unpublished Manuscript, GSB University of Chicago.

Weil, P., 1989. Nonexpected utility in macroeconomics, Quarterly Journal of Economics, Vol.105, No.1, 29-42. 
Table 1. Calibrated Parameter Values

\begin{tabular}{c|c}
\hline Preference Parameters & \\
$\delta$ & 0.999 \\
$\gamma$ & 10 \\
$\psi$ & 1.5 \\
Parameters of Stochastic Process for & \\
Consumption & \\
$\mu$ & 0.0015 \\
$\rho$ & 0.979 \\
$\sigma$ & 0.0078 \\
$\varphi_{\mathrm{e}}$ & 0.044 \\
Parameters of Stochastic Process for & \\
Dividends & 3 \\
$\phi$ & 4.5 \\
$\varphi_{\mathrm{d}}$ & \\
\hline
\end{tabular}

This table reports calibrated parameter values for the consumption and dividend growth rates processes $g_{t}$ and $g_{d, t}$, respectively. In the complete information case, the stochastic process is written as:

$$
\begin{aligned}
& g_{t+1}=x_{t}+\sigma \eta_{t+1} \\
& x_{t+1}-\mu=\rho\left(x_{t}-\mu\right)+\varphi_{e} \sigma e_{t+1} \\
& g_{d, t+1}=\phi x_{t}+\varphi_{d} \sigma u_{t+1} \\
& \eta_{t+1}, e_{t+1}, u_{t+1} \sim \operatorname{iidN}(0,1)
\end{aligned}
$$

with the three shocks $\eta_{t}, e_{t}$, and $u_{t}$ being mutually independent. These parameter values are identical to those used in Bansal and Yaron (2004). In the incomplete information case, the equations for $g_{t+1}$ and $g_{d, t+1}$ have $x_{t+1}$ rather than $x_{t}$ appearing on the r.h.s. 
Table 2. Asset Pricing Implications

\begin{tabular}{|c|c|c|c|c|c|c|c|}
\hline & & & $E\left(R_{m}-R_{f}\right)$ & $E\left(R_{f}\right)$ & $\sigma\left(\mathrm{R}_{\mathrm{m}}\right)$ & $\sigma\left(\mathrm{R}_{\mathrm{f}}\right)$ & $\sigma(p-d)$ \\
\hline \multirow[t]{2}{*}{ Data } & & Estimate & 6.33 & 0.86 & 19.42 & 0.97 & 0.29 \\
\hline & & SE & 2.15 & 0.42 & 3.07 & 0.28 & 0.04 \\
\hline \multirow[t]{5}{*}{ Complete Information } & $\gamma$ & $\psi$ & & & & & \\
\hline & 7.5 & 0.5 & 0.69 & 4.79 & 13.43 & 1.17 & 0.08 \\
\hline & 7.5 & 1.5 & 3.02 & 1.66 & 17.82 & 0.39 & 0.18 \\
\hline & 10 & 0.5 & 1.42 & 4.85 & 13.43 & 1.17 & 0.08 \\
\hline & 10 & 1.5 & 4.71 & 1.40 & 17.82 & 0.39 & 0.18 \\
\hline \multicolumn{8}{|l|}{ Incomplete Information } \\
\hline & 7.5 & 0.5 & -2.05 & 3.83 & 12.68 & 0.73 & 0.05 \\
\hline & 7.5 & 1.5 & -0.17 & 1.23 & 12.37 & 0.24 & 0.02 \\
\hline & 10 & 0.5 & -2.53 & 3.46 & 12.68 & 0.73 & 0.05 \\
\hline & 10 & 1.5 & 0.04 & 0.81 & 12.37 & 0.24 & 0.02 \\
\hline
\end{tabular}

The table reports unconditional moments implied by the long run risks model, with complete and incomplete informational assumptions. Moments for the equity premium $\left(\mathrm{R}_{\mathrm{m}}-\mathrm{R}_{\mathrm{f}}\right)$ and the risk free rate $\left(\mathrm{R}_{\mathrm{f}}\right)$ are expressed in percent per annum. Modelimplied moments are reported for a range of values for the risk aversion parameter $\gamma$ and the intertemporal elasticity of substitution (IES) $\psi$ as in Bansal and Yaron (2004). Estimates using data reported in the first row are reproduced from Table IV of Bansal and Yaron (2004). 